\title{
Asesinato premeditado de Slobodan Selenic: una mirada sobre la guerra en Yugoslavia
}

\author{
Mina APIC \\ Departamento de Romanística \\ Universidad de NoviSad \\ mina.apic@gmail.com
}

\begin{abstract}
RESUMEN
En Un asesinato premeditado de Slobodan Selenic todo idealismo está puesto bajo sospecha. El mundo burgués, con sus normas, valores, códigos y conveniencias se rompe en pedazos bajo las botas de los coroneles comunistas vencedores de la guerra. Selenic contrapone dos guerras: la de Yugoslavia y la Segunda Guerra Mundial, por boca de un viejo burgués, que ayuda a la heroína a escribir la vida intima de su abuela, y sus dos amores, símbolos del comunismo y de la burguesía culta de Belgrado. Él examina las ventajas y los abusos, pero se distancia nítidamente de una visión idealista tanto por lo que se refiere a la lucha contra el nazismo en la Segunda Guerra Mundial, como al establecimiento de un mundo más igualitario, más adecuado a las necesidades autenticas del ser humano, representado por el estado comunista, instaurado inmediatamente después de la contienda.
\end{abstract}

Palabras clave: Slododan Selenic, Asesinato premeditado, Segunda Guerra Mundial, Guerra en Yugoslavia.

\section{Slobodan Selenic's A premeditated Murder a view on the Yugoslavian War}

\begin{abstract}
In $A$ premeditated murder, by Slobodan Selenic, all idealism is put under suspicion. The bourgeois world and its rules, values, codes and conveniences is broken to pieces under the boots of the war-winning communist colonels. Selenic contrasts two wars: that of Yugoslavia and the Second World War, by means of an old bourgeois who helps the heroine to write the intimate life of her grandmother, and his two loves, symbols of communism and the cultured bourgeois Belgrade. He examines advantages and abuses but sharply distances himself from an idealistic view both as regards the struggle against Nazism in World War II and the establishment of a more egalitarian world more suited to the authentic needs of the Human being, represented by the communist state, established immediately after the contest.
\end{abstract}

Keywords: Slododan Selenic, Premediated Murder, World War II, War in Yugoslavia. 
En la literatura actual, la Segunda Guerra Mundial aparece con el enfoque centrado en sus momentos y consecuencias más dolorosos. Así ocurre, por ejemplo, en Vida de un desconocido de Andreï Makine, donde se ofrece al lector una amplia demostración de estados relativos al paso entre la vida y la muerte en el Leningrado congelado bajo el sitio: una no-ciudad, en la que el uso de las palabras se vuelve gradualmente insensato hasta quedar completamente vacío de significado. Sin embargo, en el polo opuesto a esta visión apocalíptica de Makine, aparece puesto de relieve el entusiasmo idealista de los que estaban dispuestos a sacrificarlo todo por un ideal. Es la visión que trata Maalouf en Las escalas de Levante. Aun en la visión desencantada de Makine, se ven atisbos de la ilusión que reunía a los que luchaban; un plan idealista, aunque reducido al mínimo, persiste, concentrado en los retratos de los dos personajes principales, que no hubieran dudado en arriesgar su vida por otro ser humano, sea un huérfano perdido o un ser querido. La visión desangelada de Selenic, patente en Asesinato premeditado, se inscribe en la línea cuyo enfoque es la futilidad de la guerra en general y su aspecto inhumano, poniendo en tela de juicio los abusos del idealismo colectivo. Con un espíritu frío, el escritor examina hábilmente la inclinación humana hacia los ideales, una fe pura en los valores comunes del patriotismo, en la disposición al sacrificio, pero contrastándola siempre con el reverso de estos ideales: la vulgaridad, la avidez, la crueldad, el provecho propio. Su enfoque se centra en los años 1944 y 1945, finales de la Segunda Guerra Mundial y sus secuelas en la sociedad yugoslava, momento del gran cambio debido al establecimiento del comunismo como unas de las consecuencias de las conjeturas históricas de la contienda.

La estructura de la novela está acorde con la tendencia de textos modernos a dejar siempre más libertad al lector en la reconstrucción de la historia (cf. Compagnon, 2001). Una historia que le viene ofrecida en fragmentos de varias proveniencias: testimonios verbales, escritos, cartas, archivos del tribunal. En la búsqueda de su identidad, de sus orígenes, la visión de la heroína, Jelena, se focaliza en la vida intima de su abuela, cuyo nombre lleva. El plan personal deja progresivamente espacio a lo que simbolizan los dos hombres fatales con los que se relaciona la joven burguesa: uno comandante comunista, el mayor Krsman, vencedor en dos sentidos (contra los alemanes y contra el ejercito real, que defendía el viejo sistema), y otro, el hermanastro de Jelena, su alter ego sutil y enfermizo. Denunciando los abusos del nuevo gobierno comunista, el escritor se distancia nítidamente de una visión idealista tanto de la lucha contra el nazismo en la Segunda Guerra Mundial, como del establecimiento de un mundo más igualitario.

El viejo Brana, vecino y colega de la abuela Jelena, cuyo apodo, «Carroza», encarna el modelo ejemplar del gentilhombre del viejo Belgrado burgués, introduce a la heroína y al lector en el periodo del advenimiento comunista. Su concepción de la cultura es indiscutiblemente elitista, teñida con un fuerte resentimiento, un rencor irrefrenable hacia los que le echaron de su casa en un barrio privilegiado y le dieron un pequeño habitáculo en una buhardilla. También, Selenic pone en tela de juicio el tema de los vencedores, cuya dimensión es más amplia que la injusticia acarreada por toda revolución social. Se trata del egoísmo del vencedor, el instinto del superviviente que no refleja compasión por el dolor por los fallecidos, lo que conllevaría 
un recogimiento, una modestia en silencio por respeto a los sacrificados por el ideal comun. Este egoísmo temerario del vencedor vulgar es una de las características principales del mayor Krsman. Esta línea de reflexión acerca la crítica de Selenic a la de Makine, cuyo héroe está decepcionado con la Rusia vencedora de la Segunda Guerra Mundial

la temeridad de la felicidad, la alegría evidente de los vivos. Este mundo le era tan extraño como el público del teatro de anoche lleno de uniformes de parada. [...] «El mundo de los vencedores...» Si, el vencedor es aquel que puede olvidar más rápidamente y con más desprecio que los demás. ${ }^{1}$ (Makine 2009:93)

La investigación literaria de la heroína se lleva a cabo medio siglo después, una distancia temporal que permite al lector una mirada más amplia, más englobante. El período de medio siglo de distancia está determinado precisamente por otra guerra: la de la Yugoslavia de los años noventa. Así, se contraponen dos tiempos de violencia, se subraya la debilidad humana y su inclinación a caer constantemente en el barbarismo, a dejarse llevar por los impulsos de agresión y, por otra parte, se destaca la caída del gran sueño comunista igualitario y supranacional, representado por el estado multinacional yugoslavo, instaurado inmediatamente después de la Segunda Guerra Mundial. Sin embargo, la significación de la distancia temporal esta puesta en tela de juicio por Brana, narrador de los acontecimientos de su juventud: «¿puede usted ver hoy el año cuarenta y cinco tal como era? Me temo que no. El tiempo transforma una época en una leyenda. Fea o bella, lo mismo da.» (Selenic 2016:18) El antiguo «Carroza» desarrolla una reflexión sobre la distancia entre Sinn (significado) y Bedeutung (significación), según la filosofía analítica de Gottlob Frege, aplicándola a la palabra emblemática de la época: «partisano». El tiempo ha cambiado su Sinn, alejándolo del lector moderno, y Brana se verá obligado a hacer un esfuerzo para acercarlo a su joven interlocutora:

Las palabras, en cuaanto caen de mis labios, se disipan, se tergiversan. No envejecen sólo los hombres, usted sabe. Envejecen también las palabras. Renacen, no cambiadas de forma, sino mescladas con nuevas significaciones, con otro peso y con una composición molecular diferente. Cualquiera que sea el significado actual de la palabra "partisano», en el año cuarenta y cinco significaba una cosa completamente distinta. ¡Cuánta autoadoración, cuánto odio, cuántas mentiras, historias, memorias, han confluido en esta palabra en cincuenta años! No, usted no puede saber lo que esta palabra significaba antes del amalgamiento. (Selenic 2016: 18)

Estas reflexiones de Selenic se aproximan a la de Antoin Compagnon sobre la oposición entre la corriente intencionalista y antiintencionalista en la teoría literaria. ${ }^{2}$ Selenic señala, al igual que Compagnon en referencia a los análisis de Frege y

1 Todas las traducciones al español son mías.

${ }^{2}$ Compagnon destaca que : «Desde Frege, los filósofos de la lengua diferencian el significado de un término (Sinn) y su significación (Bedeutung): «estrella matinal» y «estrella de la tarde» se refie- 
de Hirsch, la preponderancia lógica del significado sobre la significación, de la interpretación acorde con el significado originario de la época sobre la evaluación personal. Sin embargo, Compagnon subraya que

Esto no implica de manera alguna una anteposición cronológica o psicológica, dado que cuando leemos, basamos nuestras interpretaciones en estimaciones (en preentendimientos fenomenológicos), accedemos al significado a través de la significación, aunque no aceptamos siempre que nuestras estimaciones sean temporales, dispuestas al cuestionamiento en lo que concierne a su significado. (Compagnon 2001: 104)

Efectivamente, si es preferible hacer un intento de acercarse a una época y a los significados que ella abre y atribuye a diversas nociones, esto no quiere decir que la lectura óptima sería aquella que refutaría todo aporte por parte del lector, a nivel personal, o de su época

Las grandes obras son insondables; cada generación las comprende a su manera: esto significa que los lectores encuentran en ellas lo que alumbra un aspecto de su experiencia. Pero si una obra es insondable, esto no implica que no tenga su significación original, ni que la intención del escritor no sea la medida de esta. (Compagnon 2001: 104)

Sin embargo, la inclusión de nuevos matices en las palabras empleadas para describir una época no implica necesariamente que e sta se entienda mejor en el momento de vivirla, al revés, muchas teorías, de varias escuelas hermenéuticas hasta la antropología de Claude Levy-Strauss, insisten en el distanciamiento necesario como condición para el buen entendimiento y estimación de valor:

Precisamente la distancia temporal se considera como condición conveniente para la atribución de verdaderos valores. Pero otra distancia, conveniente para la selección de valores, se ofrece en la distancia geográfica, o exterioridad nacional, así que una obra se lee con más pertinencia, con perspectivas menos limitadas.(Compagnon 2001: 327)

Sin embargo, no hay certeza de que la distancia sea necesaria y siempre preferible, y tampoco puede decirse con seguridad qué distancia sería la más justa: «El argumento del futuro, o de la exterioridad, parece tranquilizador: el tiempo o la distancia hacen selección [...] Pero nada garantiza que la valorización de una obra es definitiva, que su estimación no es solo consecuencia de una moda.» (Compagnon

ren a un mismo planeta (Venus), pero de dos maneras distintas (con dos significaciones) [...] Para refutar la postura antiintencionalista, el teórico de literatura americano E. D. Hirsch ha extendido esta diferencia al texto, destacando el significado (meaning) de la significación (significance) o su uso (using) (Hirsch, 1967 y 1976) [...] El significado, según Hirsch, se refiere a lo que queda constante en la recepción del texto; responde a la pregunta «¿Que quiere decir este texto?» La significación se refiere a lo que cambia en la recepción de un texto, responde a la pregunta: «¿Qué valor tiene este texto?» [...] Al leer un texto, que sea contemporáneo o antiguo, asociamos su significado con nuestra experiencia, le damos un valor que transciende su contexto original.» (Compagnon 2001: 102-103) 
2014:327) Asimismo, la inmersión de Brana en aquella época, la distancia de medio siglo que la separa de Jelena, no impliqua que él la entienda mejor que ella. Si las palabras se han empapado de nuevos matices y aspectos, no quiere decir que esto nos aleje del entendimiento de la época, sino que puede indicar precisamente lo contrario, el enriquecimiento de nuestra perspectiva. Además, como subraya Nelson Goodman en su obra Maneras de hacer mundos, la percepción neutra, inmediata, el acceso inmediato al mundo, no es posible:

No es necesario repetir aquí los argumentos muy convincentes que Berkeley, Kant, Cassirer, Gombrich, Bruner y los demás, muy detalladamente y con gran frecuencia exponían contra la percepción sin concepción, realidad pura, inmediatez absoluta, ojo inocente [...] El discurso sobre un contenido destructurado o una realidad desconceptualizada es autoderrotador dado que la lengua misma impone una estructura, conceptualiza, atribuye propiedades. Y si la concepción sin percepción es vacía, la percepción sin concepción es ciega. (Goodman 2014: 18)

Evidentemente, Brana, Jovan y Jelena no poseían aquella realidad en forma pura, en una inmediatez absoluta de percepción sin conceptualización ni interpretación. Los tres tenían su visión, y su experiencia estaba mediatizada así por lo que entendían y opinaban de la época de la Segunda Guerra Mundial y el cambio del mundo que acarreaba. Pero no tenía que ser necesariamente más clara ni más amplia del entendimiento al que podrían llegar Jelena, la nieta y su novio Bogdan. Como subraya Goodman: «Podemos tener palabras sin mundo, pero no un mundo sin palabras y otros símbolos» (Goodman 2014:18). En fin, las palabras mismas, cuyo significado Brana sospecha haber deslizado demasiado en medio siglo, entre su época y la de su interlocutora, no reflejaban un presente puro, conllevaban consigo residuos de épocas precedentes, tal vez cada perspectiva, cada lengua, cada visión del mundo conlleva consigo residuos de las que la precedían: «La creación del mundo, tal como lo conocemos, siempre empieza con un mundo que tenemos en disposición: la creación es recreación. La antropología y la psicología de desarrollo exploran las historias sociales y individuales de tal construcción del mundo» (Goodman 2014:18).

La primera referencia explícita a la guerra, a los combates contra los alemanes en el frente de Srem, es «carnicería». Viene de la boca de Brana, cuya actitud parece al límite del cinismo, como se trasluce del comentario desencantado, que precisa su posición enunciativa, su perspectiva de narrador al inicio de la entrevista: «yo no soy un héroe, usted sabe. El heroísmo ha siempre suscitado en mí un ligero desprecio. Un héroe es un arribista o sobrestima el fin por el que se expone al peligro. Yo siempre hago lo que se espera de mí, nunca más, a veces menos de lo esperado» (Selenic 2016:24)

La actitud de «Carroza» coincide con la postura pacifista que se encuentra con frecuencia en la literatura contemporánea. Amin Maalouf, en Samarkand, lo formula en un monologo interior del héroe principal, el célebre poeta Omar Hajam: «La cosa por la que hay que matar no me puede atraer. Se vuelve fea a mis ojos, pierde su valor y se vuelve baja, por muy bella que parecía antes» (Maalouf 1998:150). La mirada de nuestra época sobre la Segunda Guerra Mundial, con todos los desastres 
humanitarios que conlleva el empleo de armas de destrucción más poderosas que nunca, está marcada ante todo por los avatares del totalitarismo y exterminios sin precedentes. Evidentemente, no se puede guardar una perspectiva idealista y alabar el heroísmo de los implicados, sino hacerse preguntas sobre cómo hemos llegado a tales extremos. Los escritores señalan la pérdida de vidas como desvalorización deplorable de la vida humana como tal, sin distinguir la pertenencia nacional o de cualquier otro tipo:

Le sorprendió el hecho de que no separaba más a los heridos rusos y alemanes... Un infierno que han creado los hombres... Confundido por la verdad que no comprendía, se precipitó a volver a un juicio más claro: el enemigo está vencido y estos alemanes que están muriendo en sus carros armados, lo han merecido... Sin embargo, aquella mirada sobre el sufrimiento de todos los hombres no se podía borrar. Volski intuía allí una gran y espantosa sabiduría que lo plegaba bajo la experiencia de un hombre muy viejo. En la Leningrado asediada creía ya ver las vidas humanas como una única vida común y tal vez precisamente aquella mirada le daba esperanza (Makine 2009:86).

La guerra en sí, a los ojos de Selenic, se resume en la palabra «carnicería», así la introduce por los ojos del testigo de la Segunda Guerra Mundial, así la pintará por sus efectos en la Yugoslavia de los años noventa, analizando al mismo tiempo el afán nacionalista y el idealismo patriótico que pueden ocultar la realidad hasta un cierto punto, pero sin poder excusar ninguna tragedia particular. Como diría Andrei Makine: «Un sufrimiento lógico de la masa humana, y, de repente, este sufrimiento individual que ninguna lógica puede justificar» (Makine 2009:81).

La crítica de Selenic está dirigida tanto contra la violencia en sí (cuyo catalizador más potente se revela en la guerra), como contra el totalitarismo del régimen que impusieron sus vencedores, que parecían haber liberado el pueblo para transformarlo en una manada dócil y maleable. La perspectiva de «Carroza» (que parece coincidir con la del mismo Selenic) es indiscutiblemente parcial, silencia toda contribución del comunismo, subrayando su lado nivelador. Efectivamente, los ideales no se pueden imponer, se inspiran, se cultivan, pero muchos se inculcaron indebidamente para imponer una conducta unívoca que denotaría adhersión a estos ideales. Como subraya Arendt, refiriéndose a los regímenes totalitarios:

La forma de tratar con los oponentes era la «rectificación del pensamiento», un elaborado procedimiento de constante moldeamiento y remoldeamiento de las mentes al cual más o menos parecía sujeta toda la población. Nunca supimos muy bien cómo funcionó este sistema en la vida cotidiana, quién estaba exento de él -es decir, quién «remoldeaba»-, y carecemos de indicaciones sobre los resultados del «lavado de cerebros», si fue duradero y produjo cambios de personalidad. (Arendt 1998: 17-18)

Estas consecuencias nefastas, hacen sombra a todo idealismo auténtico de ciertos representantes de aquella epoca, a todo arrebato liberador que ha guiado a algunos de los luchadores comunistas, a toda aspiracion a una retribución más igualitaria de bienes materiales y culturales en una sociedad humana. Igualmente, el des- 
precio de Brana hacia la grosería y la falta de cultura de los « liberadores », que es tan caústico, da prueba de su rechazo a cavar más profundo, a llevar a cabo una reflexión consecuente sobre las causas de este fenómeno: ¿no sería el antiguo sistema de clases el que los privó del acceso a una buena educatión, privilegio reservado a una capa de ciudadanos pudientes?

Es interesante señalar que, en la perspectiva de Selenic, el comunismo yougoslavo representado por los Krsman tiene una fuerte impronta nacional, sus vicios son los vicios del pueblo serbio. Bajo la mirada crítica de Selenic, la desnaturalización de la ideología comunista va de la mano de su pérdida de carácter internacional. ${ }^{3}$

Si admitimos, con Baudelaire, que todos tenemos un lado divino y uno demoníaco, o, según Todorov, la capacidad de hacer tanto el bien como el $\mathrm{mal}^{4}$, por los ojos del escritor, la guerra esta vista no como ambiente de liberación del pueblo sino precisamente como ambiente de liberación del lado satánico de lo humano. El período inmediato de postguerra, bajo la mirada de Selenic, está marcado tanto por la instauratión de una dictadura ${ }^{5}$ implacable como de una particular energía vital, de la victoria de la vida sobre la muerte.

El mayor Krsman es el paradigma del ambiente yugoslavo, y la sombra de su vitalidad es una crueldad egoísta. Jovan, su «adversario», hermanastro y amante de Jelena, es su antagonista. La voz de Jovan nos llega en un documento biográfico, un tipo de memorias íntimas, para limpiar la mente más que por otro motivo, donde igualmente deja constancia de la lucha comunista contra los traidores del partido en los finales de la guerra. Krsman no aparece nunca através de su propio testimonio, no lo deja, dado que no era proclive a la reflexión ni a confesiones escritas de ningún tipo. Los dos antagonistas aparecen a través de registros narrativos diferentes. Krsman es todo cuerpo, Jovan todo una intensa, prodigiosa y torturosa vida interior. Krsman está presente exclusivamente de manera corporal, vive en las páginas y en la mente del lector a través de su corporalidad, a través la descripción de Kojovic y la confession escrita de Jovan. Como es todo lo contrario de Jovan, personaje de amplia, matizada y compleja vida interior, lo que afecta a los dos descriptores de

${ }^{3}$ Considerando la preponderancia del elemento universal, supranacional de la ideología marxista, Arendt señala: «Incluso al final del siglo pasado, y especialmente desde la guerra franco-prusiana, más y más individuos consideraban que la organización nacional de Europa estaba anticuada porque ya no podía responder adecuadamente a los nuevos retos económicos. Este sentimiento había contribuido como argumento poderoso en la organización internacional del socialismo y se había visto, a su vez, reforzado por esta», op.cit., p.55. Sin embargo, Arent destaca igualmente que: «Los socialistas mantuvieron implícitamente intacto el concepto original de una «nación entre las naciones», pertenecientes en su totalidad a la familia de la Humanidad, pero nunca hallaron un medio para transformar esta idea en un concepto operante en el mundo de los estados soberanos.» op.cit., p.56.

${ }^{4}$ Cf. TzvetanTodorov (2008).

${ }^{5}$ La dictadura del gobierno yougoslavo no se denomina por Arendt como totalitarismo, que fue reservado a los satélites de la Unión Soviética, dada la brecha abierta entre Yougoslavia y la Unión Soviética con el famoso No al estalinismo de Tito en 1948, año de la expulsión del Partido Comunista Yougoslavo del Cominform. Como precisa Arent, «lo que pasaba en un país satélite sucedía casi en el mismo momento en otros, desde el Báltico al Adriático. Los acontecimientos fueron diferentes en las regiones no incluidas en el sistema de satélites.» Op.cit. 
Krsman es su cautivante fuerza física, es como él se impone a su alrededor, es como afecta a los que narran la historia.

En la guerra de los años noventa, el novio de Jelena, Bogdan Bilogorac, con el apodo «Cretino», es un joven combatiente de la guerra de Croacia, idealista, estudiante de geografía, movido por un sentido del honor y de pertenencia a su pueblo, hacia cuyo destino siente responsabilidad. Su vida le importa menos que el bienestar de su pueblo, al que los croatas intentan expulsar de su propia tierra. ¿Qué actitud es honorable en fin? ¿Qué postura debería tomar un hombre joven en aquellas circunstancias? Esta parece la pregunta clave, que queda abierta, a pesar de toda la agrupación de caracteres abiertamente contrarios a cualquier toma de armas: Jelena, Brana, Jovan. El «Cretino» parece único frente a todos los demás: el único idealista de la novela, que no combate no porque no tenía otras ambiciones en la vida -la guerra hace irrupción en sus estudios- sino porque tendría vergüenza de no reaccionar ante lo que empezó a suceder delante de sus ojos. Las nociones madre, patria, solidaridad, responsabilidad no están erosionadas en la mente de Bilogorac por ningún tipo de cinismo, de dudas, de absurdo. Él no ha llegado a sentir, a enfrentarse al absurdo. Este carácter monolítico, integral, sencillo, no es el del que ha frecuentado y superado el absurdo, llegando al valor supremo de solidaridad humana según el modelo de Camus. Bogdan no ha leído a Camus, ni ha llegado allí par su propia experiencia y reflexión. Él se ha quedado en el idealismo un poco ingenuo, infantil. Combatiendo con el absurdo, Camus llega a una forma de idealismo, el de la solidaridad humana como respuesta al absurdo. Pero, se puede decir que la solidaridad que siente Bilogorac, aun sin ser el fruto de una reflexión madurada, no es menos conmovedora, no se puede refutar fácilmente. El va a combatir por sentir solidaridad con los que están expuestos a las persecuciones. Él va a defender a los débiles, en cierta manera como un moderno Quijote, motivado por ideales que no se ajustan a la realidad. Pero llegamos a la pregunta fundamental: si el sentido de solidaridad (sea innato, instintivo, adquirido o conquistado a través de una reflexión penosa, de larga y tortuosa maduración de pensamiento), justifica la violencia. Dado que, estar en una guerra, disparar a otro ser humano para matarlo, es un acto de violencia. Por otro lado, dejar que maten a los inocentes sin impedirlo, ¿no sería un acto de cobardía? Selenic deja esta cuestión resonar en lo más profundo de nosotros, sin pretender llegar a una respuesta satisfactoria. La literatura está allí para elaborar cuestiones, darles forma, encarnarlas para hacernos vivirlas como propia experiencia.

En contraste con «Cretino», es el carácter reflexivo, prudente, comedido, de «Carroza» el que esta subrayando la oposición de vejez sagaz y juventud impetuosa. La prudencia reflexiva y una insaciable curiosidad intelectual, una sed de comprender el mundo, que le lanzaba a una lectura ávida de grandes clásicos literarios, lo impulsó igualmente a un intento honorable de entender la naturaleza de la violencia desmedida de los vencedores de guerra.

Sin embargo, si las mentiras de la propaganda de los vencedores se explicaban hasta un cierto punto con la imagen de un trance colectivo, sus abusos de poder y sus violencias se explican, a través de la narración de Brana, por el carácter escéptico de los paisanos serbios, que, al estallar la guerra, vistieron uniformes, lucharon, y vinieron a imponer el nuevo orden estatal. Haciéndonos pensar en la afirmación 
de Armstrong, destacada por Arendt, de que «incluso aceptando los presupuestos de la ideología comunista, todo el poder en la URSS es, en definitiva, ilegítimo» (Armstrong 1961:339 y ss.). El ataque más grave de «Carroza», la crítica acerba de Selenic, no recae en los principios de la ideología comunista como tales, no se sitúa en el plano de los principios éticos que residían en los fundamentos, sino ante todo en el suelo que la semilla de esta ideología creó, que determinó el caudal de sus abusos.

Además, en contraste con las grandes fuerzas europeas, donde desde hace un siglo la situación era drásticamente distinta: «au moment où en Allemagne la production capitaliste atteignit sa maturité, des luttes de clase avaient déjà en Angleterre et en France, bruyamment manifesté son caracter antagonique.» (Marx 1967: 25). Serbia no era un país industrialisado, y la instauracion del sistema comunista no estaba fundamentada efectivamente en la lucha del proletariado y la burguesía, dado que casi no había proletariado, considerando su débil porcentaje en la populación general. En la época de la Segunda Guerra Mundial, momento historico de instauracion del sistema comunista en Serbia, el proleteriado era una minoría y la mayoria de la población era campesina. La industria, modo principal de la producción capitalista, representaba solo un siete por ciento.

Desarrollando y matizando su mirada crítica, Selenic es hábil en cambiar registros, en construir caracteres vivos, encarnecidos y convincentes en su verdad. Sin embargo, no entra en ningún momento en una reflexión sobre los postulados de la ideología comunista. Se focaliza en subrayar los abusos y analizar los orígenes de estos abusos. El pacifismo manifiesto de «Carroza», en el que se puede ver el modelo de intelectual de la torre de marfil y aún mas su elitismo estridente, está en la base de su distanciamento de las dos corrientes de lucha contra los alemanes: tanto de los partisanos como de los cetnici, dado que el veía las filas de ambos partidos llenas de gentuza, de masas cuya falta de valores éticos le repugnaba.

El tema de las masas que invaden e imponen su orden, no se limita exclusivamente a los confines del estado yugoslavo, o de los regímenes comunistas. Desarrollado paralelamente con la denuncia de la guerra, aparece en la evolución del personaje trágico de la burgesa Jelena, y al final del libro con el enfoque en la dispersión de ilusiones y un desanhelo completo. La crítica más fulgurante de la nivelación de la vida da lugar al único momento en el que la voz de la heroína nos viene de manera directa. Su voz está formulada en la carta a Jovan, escrita después de su visita a París con los representantes del gobierno serbio, y revela su definitiva dispersión de ilusiones. No se trata únicamente de las secuelas inevitables de la guerra, que saltan a los ojos en cada estación de tren durante el viaje mismo, aun en París mismo, con su «pain national» $\mathrm{y}$ «café national», y mermelada con sacarina. En opinión de Jelena se trata de otra cosa peor: un igualitarismo nivelador, empobrecedor, que conquistó no solo Belgrado, sino todo el mundo posterior a la Segunda Guerra Mundial. El horror de la guerra, en los ojos de Jelena, no son solo los campos de exterminio ni el desastre de Hiroshima y Nagasaki, sino también el nuevo mundo de masas cuyos contornos se esbozan, ya debido a la redistribución de poderes una vez la guerra terminada:

No es Hitler quien perdió la guerra, Jovan. Nosotros la perdimos. Tú y yo. No porque a Stavra, le quitaron casas y fabricas, sino porque nos quitaron el mundo en el que era 
posible vivir cada uno según sus inclinación y diferentemente de lo que proscribe la masa borracha de sus nuevos derechos en una nueva igualdad de todo con todo. (Selenic 2016:203)

Ni siquera esta vieja Europa guardó su viejo orden de cosas. Otra época vino con la guerra, como un torrente que barrió el viejo mundo:

Creo que dentro de algunos años en Paris la mermelada nacional estará hecha con azúcar y que el café se importará de nuevo de Brasil, pero los que comerán la verdadera mantequilla y leche de vaca serán unos hombres desesperadamente nacionalizados, vulgarizados, cuyas necesidades y cuyos gustos de masa coinciden en todo. (Selenic 2016:203)

Brana, contando su historia, califica la actitud de Jelena delante del mundo al revés como distraída, lejana: «una loca inofensiva», y de esta manera, Selenic subraya lo que será uno de los grandes temas de Maalouf, entre otros representantes de la literatura contemporranea: la decomposicion del individuo intrincada con la decomposicion de la sociedad a la que pertenecía. ${ }^{6}$ Una sensación creciente de no-pertenencia causa un tipo de alienación y, a menudo, un deseo de evasión. Pero para Jelena, la evasión se revela imposible después de su viaje a Pars. Su repulsión hacia una sociedad de masas es desde luego desmesurada, llevada intencionadamente al extremo por el escritor. Entre otros efectos, se subraya el hecho de que la sociedad está dentro de nosotros en cada instante, en varios aspectos, y la decomposicion del orden social lleva consigo una perturbación profunda y dolorosa, la verdadera decomposicion del individuo. El derrumbamiento de los fundamentos de una sociedad, la desaparicion de los valores que la estructuraban, perturba inexorablemente el interior del hombre, lo descompone, amenazando destruirlo completamente. El mundo cuyas normas conocemos nos hace sentir la pertenencia, mientras que el impulso común y el futuro que se abre delante de nosotros con una multitud de posibilidades desaparece en un mundo en el que nos sentimos ajenos, que ya no nos pertenece, como el mundo de postguerra no pertenecía a la heroína de Asesinato premeditado.

\section{Referencias bibliográficas}

ARENDT, Hannah (1998): Los origenes del totalitarismo, Madrid: Taurus.

ARMSTRONG, John (1961): «The Politics of Totalitarianism. The Communist Party of the Soviet Union from 1934 to the Present», New York.

Compagnon, Antoine (2001): Demonteorije (Le démon de la théorie). Novi Sad: Svetovi (orig, Paris, Seuil, 1998.)

${ }^{6}$ En la obra de Maalouf, las variaciones de este tema podemos verlas en los personajes de Desorientados, Albert y su tentativa de suicidio y Murad que se hunde en la corrupción y el crimen. $\mathrm{O}$ Adam que huye; en Escalas de Levante, u Osian que se hunde en la locura, entre otros. 
Goodman, Nelson (2014): «Nacinistvaranjasveta» (Ways of Worldmaking). Novi Sad: Mediterran Publishing.

MAALOUF, Amin (1998): Samarkand, Beograd, IP «Ne\&Bo».

MAKINE, Andrei, (2009): Zivotnepoznatogcoveka, (Vida de un desconocido) Paideia, Beograd.

MARX, Karl (1969): «Capital, Preface a la seconde edition allemande» [En línea]. Disponible en http://classiques.uqac.ca/classiques/Marx karl/capital/capital livre 1/capital livre_1_1/fichiers_images/capital_livre_1_1_001_195.pdf [Acceso el 30 de junio de 2016].

SELENIC, Slobodan (2016): Ubistvo s predumisljajem, Beograd, Laguna.

TODOROV, Tzvetan (2008): El miedo a los barbarios, Galaxia Gutenberg. 